\title{
Estimation of Total Phenolic and Flavonoid Contents in Some Medicinal Plants and Their Antioxidant Activities
}

\author{
Bedraj Pandey ${ }^{1}$ and Meena Rajbhandari ${ }^{2}$ \\ ${ }^{1}$ Central Department of Chemistry, Tribhuvan University, Kathmandu, Nepal \\ ${ }^{2}$ Research Center for Applied Science and Technology, Tribhuvan University, \\ Kathmandu, Nepal \\ e-mail: karmacharyameena@gmail.com
}

\begin{abstract}
Quercetin was isolated from ethyl acetate fraction of a methanol extract of the outer scale of onion by repeated sephadex LH-20 column chromatography. Methanol, 50\% aqueous methanol and 70\% aqueous acetone extracts of different parts of four medicinal plants, Ficus benghalensis, Elaeocarpus sphaericus, Ipomea carnea and Azeratum conyzoides were prepared and screened for total phenolic and flavonoid contents and free radical scavenging activity. The total phenolics contents were measured spectrophotometrically by using Folin-Ciocalteu reagent and total flavonoids content by using aluminum chloride colorimetric method. Free radical scavenging activity was evaluated using 2,2-diphenyl-1-picryl-hydrazyl (DPPH) assay. All the investigated medicinal plant extracts contained high amount of phenolics. The highest amount was detected in 70\% aqueous acetone extract of $E$. sphaericus (298.8 $\pm 9.03 \mathrm{mg} \mathrm{GAE} / \mathrm{g}$ extract) and lowest amount in $50 \%$ aqueous methanol extract of $F$. benghalensis $(6.7 \pm 0.73 \mathrm{mg}$ $\mathrm{GAE} / \mathrm{g}$ extract). The highest amount of flavonoid was found in methanol extract $(78.2 \pm 2.72 \mathrm{mg}$ quercetin/g extract) and the lowest amount was detected in 50\% aqueous methanol extract $(2.1 \pm 0.25 \mathrm{mg}$ quercetin/g extract) of $F$. benghalensis. DPPH free radical scavenging assay was carried out only in $70 \%$ acetone extracts. The highest $\mathrm{IC}_{50}$ value was observed for E. sphaericus $(34.0 \mu \mathrm{g} / \mathrm{ml})$. A strong linear correlation between total phenolic content and antioxidant activity was found indicating that the major antioxidants are phenolics.
\end{abstract}

Key words: antioxidant activity, gallic acid, medicinal plants, quercetin, total flavonoids phenolics

\section{Introduction}

Reactive oxygen and/or nitrogen species such as superoxide anion, hydrogen peroxide, hydroxyl radical and peroxy-nitrite free radicals are constantly produced as the normal products of cellular metabolism. When the cellular concentration of oxidant species is increased to an extent that overcome the endogenous antioxidant defense system, oxidative stress occurs, leading to lipid, protein and DNA damage which is considered a main factor contributing to carcinogenesis and evolution of cancer, and may cause many disorders such as diabetes, asthma, inflammation, premature aging, cardiovascular and neurodegenerative diseases (Ames et al. 1993, Khan et al. 1995). Due to the ability of natural phenolic compounds to scavenge and reduce the production of free radicals and act as transition metal chelators, they can exert a major chemopreventive activity (Kampa et al. 2007). Quercetin and other phenols (Alia et al. 2006, Aherne \& O'Brine 1999, Johnson \& Loo 2000) were shown to exert protective effects against cellular oxidative damage in different human cell lines. In addition, phenolic compounds possess antiangiogenesis effects (Mojzis et al. 2008), which is an important aspect in the inhibition of tumor growth, invasion and metastasis.

Medicinal plants contain a wide variety of phytochemicals such as phenolics, flavonoids, chlorophyll derivatives, tocopherols, carotenoids and ascorbic acid as natural antioxidants. However, recently phenolics have been considered powerful antioxidants in vitro and proved to be more potent than vitamin C and E (Rice-Evans et al. 1995, Rice- 
Evans et al. 1996, Scalbert et al. 2005). These natural antioxidants act by scavenging free radical species or by inhibiting the generation of reactive species during the course of normal cell metabolism, thus preventing damage to lipids, proteins and nucleic acids, and eventual cellular damage and death (Cotelle et al. 2001). Plant phenolics appear to exhibit different anticarcinogenic mechanisms including inactivating potentially carcinogenic reactive electrophiles and scavenging reactive oxygen species that may initiate tumor production (Heinonen et al. 1998, Ames et al. 1993). Thus, phytochemicals responsible for such antioxidant activity should be isolated and used for the prevention and treatment of free redical related disorders.

Nepal is a natural store house of medicinal plants. Approximately 70 to $80 \%$ of the population of Nepal depends on traditional medicines. Indigenous people residing in different belts depend on local plants and plant products to meet their daily requirements for food, fodder and medicines. Local herbs and other plant resources found in rural area are the principle source of medicines for treating diseases since time immemorial. Despite widespread use of medicinal plants, little is known about their chemical composition while quantitative data on phenolics content and the antioxidant potential are missing which is the subject of investigation. In our previous study, we have quantified the total flavonoids content in different parts of Camellia plants, and total phenolics content in different medicinal herbs and also assessed the selected extracts for their antioxidant activity using DPPH free radical (Acharya et al. 2013, Gewali et al. 2013).

The aim of the present study is to evaluate the total phenolics and flavonoids contents in different extracts prepared from different parts of medicinal plants and compare the radical scavenging activity using 2,2diphenyl-1-picrylhydrazyl (DPPH) free radical. In addition, the relationship between the DPPH radical scavenging activity and total phenolic content of some extracts are also established.

\section{Methodology}

Chromatographic materials and chemicals

Thin layer chromatography foils (precoated Silica gel 60 $\mathrm{GF}_{254}, 0.2 \mathrm{~mm}$ ) were purchased from Merck, Darmstadt, Germany. Sephadex LH-20 was purchased from Pharmacia Biotech, Uppasala, Sweden. DPPH was purchased from
Sigma Chemical Company, USA. Gallic acid was purchased from Merck, Darmstadt, Germany. Authentic quercetin was provided by Prof. S. M Tuladhar, Research Centre for Applied Science and Technology, RECAST, Tribhuvan University. Aluminum chloride reagent and Folin Ciocalteu reagent were purchased from SD finechemicals. All other chemicals were of analytical grade.

\section{Plant materials}

Plant materials were collected from Kirtipur, Kathmandu, Nepal on February 2013. They were authenticated by comparision with the voucher specimens deposited at the National Herbarium at Godwari. The name of plants, their local names and collected parts are given in Table 1.

Table 1. Name of plants, local names and collected parts

\begin{tabular}{|c|c|c|}
\hline Name of Plants & Local Names & Collected Parts \\
\hline Ageratum conizoides Linn. & Raawanne & Whole plant \\
\hline Allium cepa Linn. & Pyaaj & Outer scales \\
\hline $\begin{array}{l}\text { Elaeocarpus sphaericus } \\
\text { (Gaertn.) K. Schum }\end{array}$ & Rudraksha & Leaves \\
\hline Ficus benghalensis Linn. & Bar & Leaves \\
\hline Ipomea carnea Jacq & Beshram & Leaves \\
\hline
\end{tabular}

Extraction of dry scales of onion and isolation of quercetin

Finely crushed onion scale ( $200 \mathrm{~g}$ ) was extracted with methanol (1 liter) for twelve hours in a soxhlet extractor. The methanol extract was concentrated under reduced pressure in a rotavapour to get viscous liquid $(51.4 \mathrm{~g})$ which was suspended in $100 \mathrm{ml}$ distilled water and then extracted with hexane $(200 \mathrm{ml} x 4)$ in a separatory funnel. The aqueous layer was again extracted with ethyl acetate (200 $\mathrm{ml} \times 5)$. The ethyl acetate layer was collected and evaporated in a rotavapour under reduced pressure and $6 \mathrm{~g}$ crude extract was chromatographed on a sephadex LH- 20 column filled with $97 \mathrm{~g}$ sephadex and eluted with methanol. Sub-fractions were collected and monitored by TLC on silica gel $\mathrm{GF}_{254}$ using solvent system ethyl acetate - methanol - water, EMW (100 : $10: 5$ ). The sub-fractions were pooled into four major fractions on the basis of TLC character. The quercetin accumulated fraction $(2.1 \mathrm{~g})$ was further chromatographed on a sephadex LH- 20 column filled with $97 \mathrm{~g}$ sephadex and eluted with $75 \%$ aqueous methanol. Sub-fractions were collected and monitored by TLC and pooled into five major 
Bedraj Pandey \& Meena Rajbhandari/Estimation of Total Phenolic.

fractions. The fraction containing quercetin was concentrated and purified by recrystallization with hot water to get $700 \mathrm{mg}$ of yellow powder.

\section{Preparation of extracts for the determination of total phenolics and flavonoids}

An amount of $20 \mathrm{~g}$ each of the dried and powdered plant materials was extracted with methanol $(200 \mathrm{ml})$ in a soxhlet extraction apparatus for 10 hours. The residue was extracted with $50 \%$ aqueous methanol under reflux for six hours. Similarly, $20 \mathrm{~g}$ each dried and powdered sample was percolated with $70 \%$ acetone and subjected to ultrasound-assisted extraction for 15 minutes. The extracts were filtered and the solvent was evaporated in a rotary evaporator under reduced pressure to get respective extracts.

\section{Determination of total phenolic content in different extracts Preparation of standard}

The total phenolic content in plant extracts was determined by using Folin-Ciocalteu colourimetric method based on oxidation-reduction reaction (Waterhouse 2002). Various concentrations of gallic acid solutions in methanol $(100,75,50,25$ and $10 \mu \mathrm{g} /$ $\mathrm{ml}$ ) were prepared. In a $20 \mathrm{ml}$ test tube, $1 \mathrm{ml}$ gallic acid of each concentration was added and to that $5 \mathrm{ml}$ Folin-Ciocalteu reagent (10\%) and $4 \mathrm{ml} 7 \% \mathrm{Na}_{2} \mathrm{CO}_{3}$ were added to get a total volume of $10 \mathrm{ml}$. The blue coloured mixture was shaken well and incubated for 30 minutes at $40{ }^{\circ} \mathrm{C}$ in a water bath. Then, the absorbance was measured at $760 \mathrm{~nm}$ against blank. All the experiments were carried out in triplicate. The average absorbance values obtained at different concentrations of gallic acid were used to plot the calibration curve.

\section{Preparation of sample}

Various concentrations of the extracts $(200,100,50$ and $25 \mu \mathrm{g} / \mathrm{ml}$ ) were prepared. Following the procedure described for standard, absorbance for each concentration of the extract was recorded. Total phenolic content of the extracts was expressed as mg gallic acid equivalents (GAE) per gram dry extract $(\mathrm{mg} / \mathrm{g})$. Total phenolic content in all samples were calculated using the formula: $\mathrm{C}=\mathrm{cV} / \mathrm{m}$ where, $\mathrm{C}=$ total phenolic content $\mathrm{mg}$ GAE/g dry extract, $\mathrm{c}=$ concentration of gallic acid obtained from calibration curve in $\mathrm{mg} / \mathrm{ml}, \mathrm{V}=$ volume of extract in $\mathrm{ml}$, $\mathrm{m}=$ mass of extract in gram.

\section{Determination of total flavonoid content in different extracts Preparation of standard}

The total flavonoid content was determined by aluminum chloride colorimetric assay (Zhishen et al. 1999). Various concentrations of standard quercetin $(2.0,1.0,0.5$ and $0.25 \mathrm{mg} / \mathrm{ml})$ were prepared. An aliquot of $1 \mathrm{ml}$ quercetin of each concentration in methanol was added to a $10 \mathrm{ml}$ volumetric flask containing $4 \mathrm{ml}$ double distilled water. At the zero time, $0.3 \mathrm{ml} 5 \%$ sodium nitrite was added, after $5 \mathrm{~min}, 0.3 \mathrm{ml}$ of $10 \%$ $\mathrm{AlCl}_{3}$ was added and at $6 \mathrm{~min}, 2 \mathrm{ml}$ of $1 \mathrm{M}$ sodium hydroxide was added to the mixture. Immediately, the total volume of the mixture was made up to $10 \mathrm{ml}$ by the addition of $2.4 \mathrm{ml}$ double distilled water and mixed thoroughly. Absorbance of the pink color mixture was determined at $510 \mathrm{~nm}$ versus a blank containing all reagents except quercetin. The average absorbance values obtained at different concentrations of quercetin were used to plot the calibration curve.

\section{Preparation of sample}

Various concentrations of the extracts $(2.0,1.0,0.5$ and $0.25 \mathrm{mg} / \mathrm{ml}$ ) were prepared. Following the procedure described for standard, absorbance for each concentration of extract was recorded. Total flavonoid content of the extracts was expressed as mg quercetin equivalents $(\mathrm{QE})$ per gram of dry extract $(\mathrm{mg} / \mathrm{g})$. Total flavonoid content is calculated by using the formula: $\mathrm{C}=\mathrm{cV} / \mathrm{m}$ where, $\mathrm{C}=$ total flavonoid content $\mathrm{mg} \mathrm{QE} / \mathrm{g}$ dry extract, $\mathrm{c}=$ concentration of quercetin obtained from calibration curve in $\mathrm{mg} / \mathrm{ml}, \mathrm{V}=$ volume of extract in $\mathrm{ml}, \mathrm{m}=$ mass of extract in gram.

\section{Statistical analysis}

All the experiments were carried out in triplicates and data reported are mean \pm standard deviation. Calculation of linear correlation coefficient and correlation analysis were carried out using MS Office Excel 2007. The linear regression equation for a straight line is, $y=m x+c$ where, $y=$ absorbance of extract, $m$ $=$ slope of the calibration curve, $\mathrm{x}=$ concentration of extract, $\mathrm{c}=$ intercept. Using this regression equation, concentrations of extracts were calculated. From the calculated values of concentration of each extract, the total phenolics and flavonoid content were calculated. 


\section{Determination of antioxidant activitiy using 2,2-diphenyl-1-picrylhydrazyl free radical}

Antioxidant activity of the selected extracts was assessed using DPPH free radical (Brand-William et al. 1995). DPPH solution (0.1 mM) was prepared by dissolving $3.9 \mathrm{mg}$ of DPPH in $100 \mathrm{ml}$ methanol and stirred overnight at $4^{\circ} \mathrm{C}$. Thus, prepared purple colored $\mathrm{DPPH}$ free radical solution was stored at $-20^{\circ} \mathrm{C}$ for further use.

Three different concentrations ( 5,10 and $15 \mu \mathrm{g} / \mathrm{ml})$ of methanolic solutions of each extract were prepared by the serial dilution of the stock solution of the respective extract. To each $0.5 \mathrm{ml}$ extract solution, $2.5 \mathrm{ml} 0.1 \mathrm{mM}$ methanolic DPPH solution was added. A control was prepared by mixing $0.5 \mathrm{ml}$ distilled water and $2.5 \mathrm{ml} 0.1$ $\mathrm{mM}$ methanolic DPPH solution. These samples were shaken well and kept in dark for $30 \mathrm{~min}$ at room temperature. The absorbance was measured at $517 \mathrm{~nm}$ against the blank solution consisting $2.5 \mathrm{ml} \mathrm{MeOH}$ and $0.5 \mathrm{ml}$ distilled water. The radical scavenging activity was expressed as the radical scavenging percentage using the equation where; $A_{S}=$ absorbance of sample solution, $A_{b}=$ absorbance of blank and $A_{C}=$ absorbance of control.

$\%$ scavenging $=\left[\frac{(A s-A b)}{A c}\right] \times 100$

$\mathrm{IC}_{50}$ value is the concentration of sample required to scavenge $50 \%$ of DPPH free radical and was calculated from the graph of radical scavenging activity against the concentration of extracts. Statistically, the correlation between antioxidant activity and total phenolic and flavonoid content was determined by plotting $\mathrm{IC}_{50}(\mu \mathrm{g} / \mathrm{ml})$ against total phenolics and total flavonoids (mg/g).

\section{Results and Discussion Isolation and characterization of quercetin from onion scale}

Finely powdered onion scale was extracted with methanol and the solvent was evaporated to get viscous liquid which was then extracted with ethyl acetate. The ethyl acetate soluble portion was subjected to repeated chromatography on sephadex LH- 20 column and quercetin was isolated. which was purified by recrystallization with hot water. On thin layer chromatogram, it appeared as light yellow spot, turned into dark yellow spot on exposure to air, brown colored spot under UV $254 \mathrm{~nm}$, bright yellow under
UV $366 \mathrm{~nm}$, dark yellow when exposed to ammonia vapour. Thin layer chromatography $\left(\mathrm{R}_{\mathrm{f}} 0.79\right.$ in butanolacetic acid-water 4:1:5; 0.88 in chloroform-acetic acidwater 10:9:1; 0.87 in ethylacetate-methanol-water 100:10:5; 0.45 in toluene-ethylacetate-formic acid 10:8:1) and the melting point $\left(315-317^{\circ} \mathrm{C}\right)$ of the isolated quercetin is in good agreement with the authentic quercetin. The UV spectrum of the isolated and authentic quercetin showed absorption bands at 230 and $358 \mathrm{~nm}$. The IR spectrum of the isolated and authentic quercetin has a broad band around 3600$2400 \mathrm{~cm}^{-1}$ region corresponding to the superimposed aliphatic and aromatic $\mathrm{C}-\mathrm{H}$ and phenolic $\mathrm{O}-\mathrm{H}$ stretching. Other stretchings were comparable with IR spectra of authentic quercetin.

\section{Amount of different extracts obtained under different extraction conditions}

For the determination of total phenolics and total flavonoids in plant extracts, different extraction approaches such as soxhlet using methanol, reflux using $50 \%$ aqueous methanol and ultrasound assisted using $70 \%$ acetone were applied. The yield of the extract varied according to the extraction method and plant samples used. The results are shown in Table 2. Among the plants included in this study, both the highest and the lowest amount of extracts were obtained with methanol (7.74 g) and 50\% aqueous methanol $(0.31 \mathrm{~g})$ extract of $E$. sphericus respectively.

Table 2. Amount of extracts (gram) from $20 \mathrm{~g}$ of plant materials

\begin{tabular}{l|c|c|c}
\hline Name of Plant & $\begin{array}{c}\text { Methanol } \\
\text { Extract }\end{array}$ & $\begin{array}{c}50 \% \\
\text { Methanol } \\
\text { Extract }\end{array}$ & $\begin{array}{c}70 \% \\
\text { Acetone } \\
\text { Extract }\end{array}$ \\
\hline F. benghalensis & 4.95 & 0.63 & 5.45 \\
E. sphaericus & 7.74 & 0.31 & 6.74 \\
I. carnea & 2.17 & 0.43 & 3.41 \\
A. conizoides & 2.08 & 0.71 & 2.10 \\
\hline
\end{tabular}

Total phenolic content in different plant extracts

The total phenolic content in plant extract was determined by using Folin-Ciocalteu (F-C) colourimetric method. Gallic acid was used as a standard compound. The absorbance values obtained at different concentrations of gallic acid was used for the construction of calibration curve (Fig 1). F-C method is based on the transfer of electrons in alkaline medium 
from phenolic compounds to phosphomolybedic/ phosphotungstic acid complexes to form blue coloured complexes, $\left(\mathrm{PMoW}{ }_{11} \mathrm{O}_{40}\right)^{-4}$ that are determined spectrophotometrically at $760 \mathrm{~nm}$. Total phenolic content of the extracts was calculated from the regression equation of calibration curve ( $\mathrm{y}=$ $\left.0.013 \mathrm{x}, \mathrm{R}^{2}=0.999\right)$ and expressed as mg gallic acid equivalents (GAE) per gram of extract $(\mathrm{mg} / \mathrm{g})$. The results are presented in Table 2.

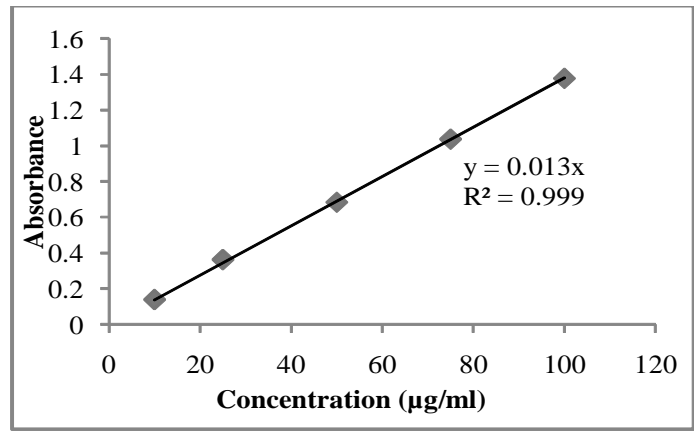

Fig. 1. Callibration curve for standard gallic acid

\section{Total flavonoid content in different plant extracts}

Total flavonoid content in the extracts was determined by reaction with sodium nitrite followed by the development of colored flavonoid-aluminum complex formation using aluminum chloride in alkaline condition which was monitored spectrophotometrically at maximum wavelength of 510 $\mathrm{nm}$. Quercetin was used as a standard compound. The absorbance values obtained at different concentrations of quercetin was used for the construction of calibration curve (Fig 2). Total Flavonoids content of the extracts was calculated from the regression equation of calibration curve $\left(y=0.004 x ; R^{2}=0.995\right)$ and expressed as $\mathrm{mg}$ quercetin equivalent (QE) per gram extract $(\mathrm{mg} / \mathrm{g})$. The results are presented in Table 3.

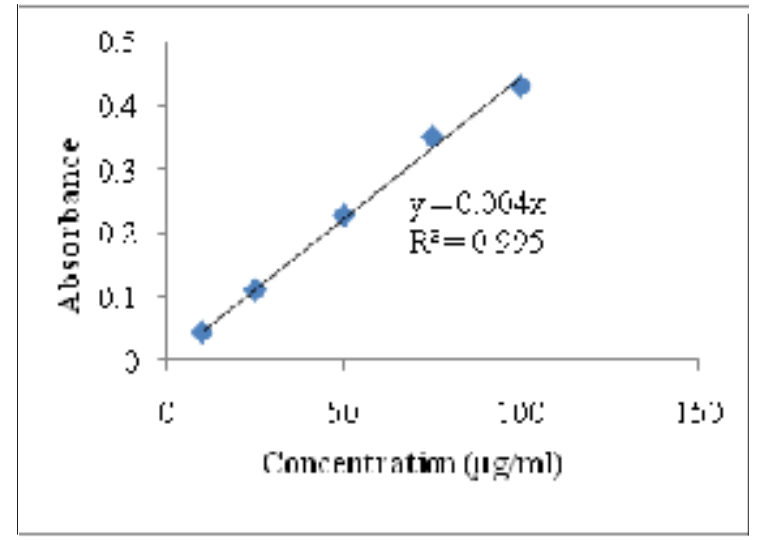

Fig. 2. Callibration curve of standard quercetin

Table 3. Total phenolic, TPand flavonoid, TF content in different extracts and their ratio

\begin{tabular}{|c|c|c|c|c|c|c|c|c|c|}
\hline Name of Plant & $\begin{array}{l}\text { Methanol } \\
\text { mg GAE/g }\end{array}$ & $\begin{array}{l}\text { Methamol } \\
\mathrm{mg} \mathrm{QE} / \mathrm{g}\end{array}$ & $\begin{array}{l}\text { Ratio } \\
\text { TFTP }\end{array}$ & $\begin{array}{c}50 \% \\
\text { Methamol me } \\
\text { GAE }\end{array}$ & $\begin{array}{c}50 \% \\
\text { Methamol } \\
\text { mg QE'g }\end{array}$ & $\begin{array}{l}\text { Ratio } \\
\text { TF/TP }\end{array}$ & $\begin{array}{c}70 \% \\
\text { Acetone } \\
\text { mg GAEg }\end{array}$ & $\begin{array}{l}70 \% \\
\text { Aoetone } \\
\text { mg QE } / g\end{array}$ & $\begin{array}{l}\text { Ratio } \\
\text { TF/TP }\end{array}$ \\
\hline A corizcides & $182 \pm 181$ & $12.7 \pm 2.24$ & 0.697 & $25.0 \pm 1.17$ & $2.5 \pm 0.10$ & 0.006 & $12.1 \pm 0.23$ & $962 \pm 0.47$ & 0.795 \\
\hline E. sphaericus & $2476 \pm 3.91$ & $61.9 \pm 2.83$ & 0.250 & $30.6 \pm 0.76$ & $7.7 \pm 0.73$ & 0.251 & $298.7 \pm 903$ & $44.1 \pm 421$ & 0.147 \\
\hline F. benghalensis & $212.4 \pm 3.46$ & $78.2 \pm 2.71$ & 0.368 & $6.7 \pm 0.73$ & $2.1 \pm 0.25$ & 0.313 & $1313 \pm 1.42$ & $780 \pm 2.44$ & 0.594 \\
\hline I. canea & $470 \pm 393$ & $19.2 \pm 1.62$ & 0.408 & $60.4 \pm 0.86$ & $11.3 \pm 1.28$ & 0.187 & $34.4 \pm 1.74$ & $100 \pm 000$ & 0.290 \\
\hline
\end{tabular}

Total phenolic content in methanol and $70 \%$ acetone extracts were relatively high when compared with $50 \%$ aqueous methanol extract in $F$. benghalensis and E. sphaericus. However, in the case of I. carnea and A. conizoides, total phenolic content in $50 \%$ aqueous methanol extracts were relatively high when compared with methanol and $70 \%$ aqueous acetone extracts. F. benghalensis and E. sphericus contained higher amount of phenolic compounds than $I$. carnea and A. conizoides in methanol and $70 \%$ aqueous acetone extracts. The highest amount of phenolic was detected in $70 \%$ aqueous acetone extract of E. sphericus $(298.7 \pm 9.03 \mathrm{mg} \mathrm{GAE} / \mathrm{g})$ and lowest amount in $50 \%$ aqueous methanol extract of $F$. benghalensis $(6.7 \pm 0.73 \mathrm{mg} \mathrm{GAE} / \mathrm{g})$.

In most cases, it was found that total flavonoid content in methanol and $70 \%$ aqueous acetone extracts was relatively high when compared with $50 \%$ aqueous methanol extract. In all cases total flavonoid content in methanol extract was found to be higher than $70 \%$ aqueous acetone extract and $50 \%$ aqueous methanol 
extract. The highest total flavonoid content was found in methanol extract $(78.1 \pm 2.71 \mathrm{mg} \mathrm{QE} / \mathrm{g})$ and the lowest was found in $50 \%$ aqueous methanol extract $(2.1 \pm 0.25$ $\mathrm{mg} \mathrm{QE} / \mathrm{g}$ ) of $F$. benghalensis. As an exception, in $I$. carnea, the lowest flavonoid content was found in $70 \%$ aqueous acetone extract $(10.0 \pm 0.00 \mathrm{mg} \mathrm{QE} / \mathrm{g})$ and the highest was found in methanol extract $(19.2 \pm 1.62$ $\mathrm{mg} \mathrm{QE} / \mathrm{g})$.

The ratios of total flavonoid to total phenolic content were found to be different in different extracts. In the case of methanol extract of $A$. conizoides, the greatest ratio (0.69) was observed whereas in E. sphaericus, the lowest ratio $(0.25)$ was observed which indicated that $69 \%$ of total phenolics in A. conizoides are flavonoids and only $25 \%$ of total phenolics in $E$. sphaericus are flavonoids. Similarly, in $70 \%$ acetone extract, $79 \%$ of total phenolics are flavonoids in $A$. conizoides and only $15 \%$ of total phenolics are flavonoids in E. sphaericus. However, in the case of $50 \%$ aqueous methanol, the highest ratio $(0.31)$ was observed in F. benghalensis and the lowest (0.09) was observed in $A$. conizoides which indicated that only $31 \%$ and $9 \%$ are flavonoids in the case of $F$. benghalensis and A. conizoides respectively.

\section{Determination of antioxidant activity}

DPPH assay was carried out for $70 \%$ acetone extracts of medicinal plants. The absorbance values were measured at wavelength $517 \mathrm{~nm}$ for different concentrations of extracts and the control. These values were used to calculate the percentage inhibitions of DPPH radicals against the samples. The $\mathrm{IC}_{50}$ values of various extracts were calculated from the percentage inhibitions at various concentrations are given in Table 4 . The calculated percentage of inhibition showed that all the four extracts have shown antioxidant activity. The extract with the highest phenolic content showed the greatest radical scavenging activity.

Table 4. $\mathrm{IC}_{50}$ values of various extracts

\begin{tabular}{l|l|l}
\hline Plant & $\begin{array}{l}\mathrm{IC}_{90} \\
(\mu g / \mathrm{mL})\end{array}$ & $\begin{array}{l}\text { TPC (mg } \\
\text { GAEIg) }\end{array}$ \\
\hline A. conizoides & 312.000 & 12.192 \\
E. spharicus & 34000 & 298.769 \\
F. Benghalensis & 135.000 & 131.326 \\
I. camea & 238.000 & 34.442
\end{tabular}

\section{Correlation between DPPH radical scavenging activity $\left(\mathrm{IC}_{50}\right)$ and total phenolic content}

The correlation between antioxidant activity and total phenolic content had been determined by plotting $\mathrm{IC}_{50}$ $(\mu \mathrm{g} / \mathrm{ml})$ against total phenolic content (mg GAE/g). The relation between total phenolic contents and free radical scavenging activity, FRSA of the samples is shown in Fig. 3.

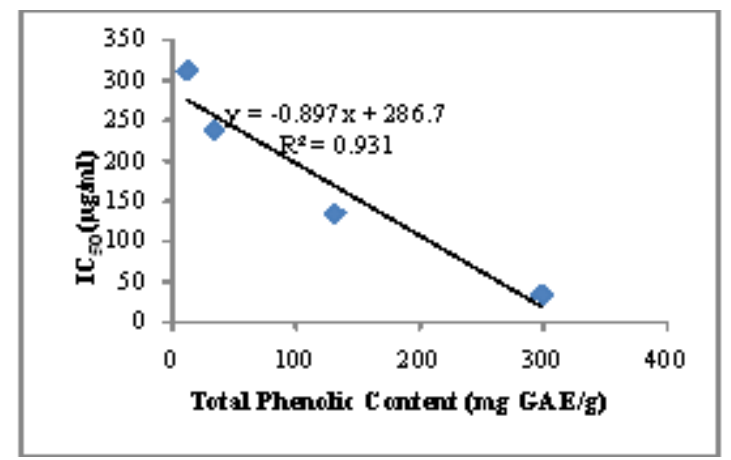

Fig. 3. Correlation between $\mathrm{IC}_{50}$ value and total phenolic content

A direct correlation between radical scavenging activity $\left(\mathrm{IC}_{50}\right)$ and TPC of the samples was demonstrated by linear regression analysis. The relationship between radical scavenging activity (Y) and total phenolic content $(\mathrm{X})$ revealed coefficient of correlation $\left(\mathrm{R}^{2}\right)$ of 0.931 . It can be stated that scavenging effects of extracts is not limited to phenolic compounds but other antioxidant secondary metabolites in the extracts such as volatile oils, carotenoids and vitamins may also play significant role (Javanmardi et al. 2003).

\section{Acknowledgements}

This work was partly supported by the grant of Volkswagen Foundation, Germany and Nepal Academy of Science and Technology, Khumaltar. The authors are grateful to Prof. U. Lindequist, University of Greifswald for providing authentic gallic acid and Sephadex and Prof. S. M. Tuladhar, RECAST, T.U. for providing authentic quercetin and DPPH.

\section{References}

Acharya, P. P., G. R. Gewali and M. Rajbhandari. 2013. Isolation of catechin from Acacia catechu Willdenow, estimation of total flavonoid content in Camellia 
Bedraj Pandey \& Meena Rajbhandari/Estimation of Total Phenolic

sinensis Kuntze and Camellia sinensis Kuntze var. assamica collected from different geographical region and their antioxidant activity. Scientific World 11: $32-36$

Aherne, S.A. and N. M. O'Brien. 1999. Protection by the flavonoids myricetin, quercetin, and rutin against hydrogen peroxide-induced DNA damage in Caco-2 and Hep G2 cells. Nutrition and Cancer 34: 160-166.

Alia, M., R. Mateos, S. Ramos, E. Lecumberri, L. Bravo and L. Goya. 2006. Influence of quercetin and rutin on growth and antioxidant defense system of a human hepatoma cell line (HepG2). European Journal of Nutrition 45: 19-28.

Ames, B. N., M. K. Shigenaga and T. M. Hagen. 1993. Oxidants, antioxidants and the degenerative diseases of aging. Proceeding of National Academy of Science U.S.A. 90 (17) : 7915-7922.

Brand-William, W., M. E. Cuvelier and C. Berset. 1995. Use of a free radical method to evaluate antioxidant activity Lebensmittel-wissenschaft und Technologie $\mathbf{2 8}$ (1): 25-30.

Cotelle, N. 2001. Role of flavonoids in oxidative stress. Current Topics in Medicinal Chemistry 1: 569-590.

Gewali, G. R., P. P. Acharya and M. Rajbhandari. 2013. Isolation of gallic acid and estimation of total phenolic content in some medicinal plant and their antioxidant activity. Nepal Journal of Science and Technology 14: 95-102

Heinonen, M. I., A. S. Meyer and E. N. Frankel. 1998. Antioxidant activity of berry phenolics on human lowdensity lipoprotein and liposome oxidation. Journal of Agriculture and Food Chemistry 46: 4107-4112.

Javanmardi J., C. Stushnoff, E. Locke and J. M. Vivanco. 2003. Antioxidant activity and total phenolic content of Iranian Ocimum accessions. Food Chemistry 83: 547-550.
Johnson, M.K. and G. Loo. 2000. Effects of epigallocatechin gallate and quercetin on oxidative damage to cellular DNA. Mutation Research 459: 211-218.

Kampa, M., A. P. Nifli, G. Notas and E. Castanas. 2007. Polyphenols and cancer cell growth. Reviews of Physiology, Biochemistry and Pharmacology 159: 79-113.

Khan, A.U. and T. Wilson. 1995. Reactive oxygen species as cellular messengers. Chemistry and Biology 2: $437-445$

Mojzis, J., L. Varinska, G. Mojzisova, I. Kostova and L. Mirossay. 2008. Antiangiogenic effects of flavonoids and chalcones. Pharmacological Research 57: 259265.

Rice-Evans, C.A., N. J. Miller, P. G. Bolwell, P. M. Bramley and J. B. Pridham. 1995. The relative antioxidant activities of plant-derived polyphenolic flavonoids. Free Radical Research 22: 375-383.

Rice-Evans, C.A., N. J. Miller and G. Paganga. 1996. Structure-antioxidant activity relationships of flavonoids and phenolic acids. Free Radical Biology and Medicine 20: 933-956.

Scalbert, A., C. Manach, C. Morand, C. Remesy and L. Jimenez. 2005. Dietary polyphenols and the prevention of diseases. Critical Review of Food Science and Nutrition 45: 287-306.

Waterhouse, A. 2002. Determination of total phenolics. In: Current protocols in food analytical chemistry (Ed Wrolstad, R. E). John Wiley and Sons, New York, Units I1.1.1-I1.1.8.

Zhishen, J., T. Mengcheng and W. Jianming. 1999. The determination of ûavonoid contents in mulberry and their scavenging effects on superoxide radicals. Food Chemistry 64: 555-559. 
Nepal Journal of Science and Technology Vol. 15, No.1 (2014) 53-60 